\title{
THE REACTIONS OF ÆOLOSOMA TO CHEMICAL STIMULI
}

BY

\author{
H. G. KRIBS
}

With Two Figures

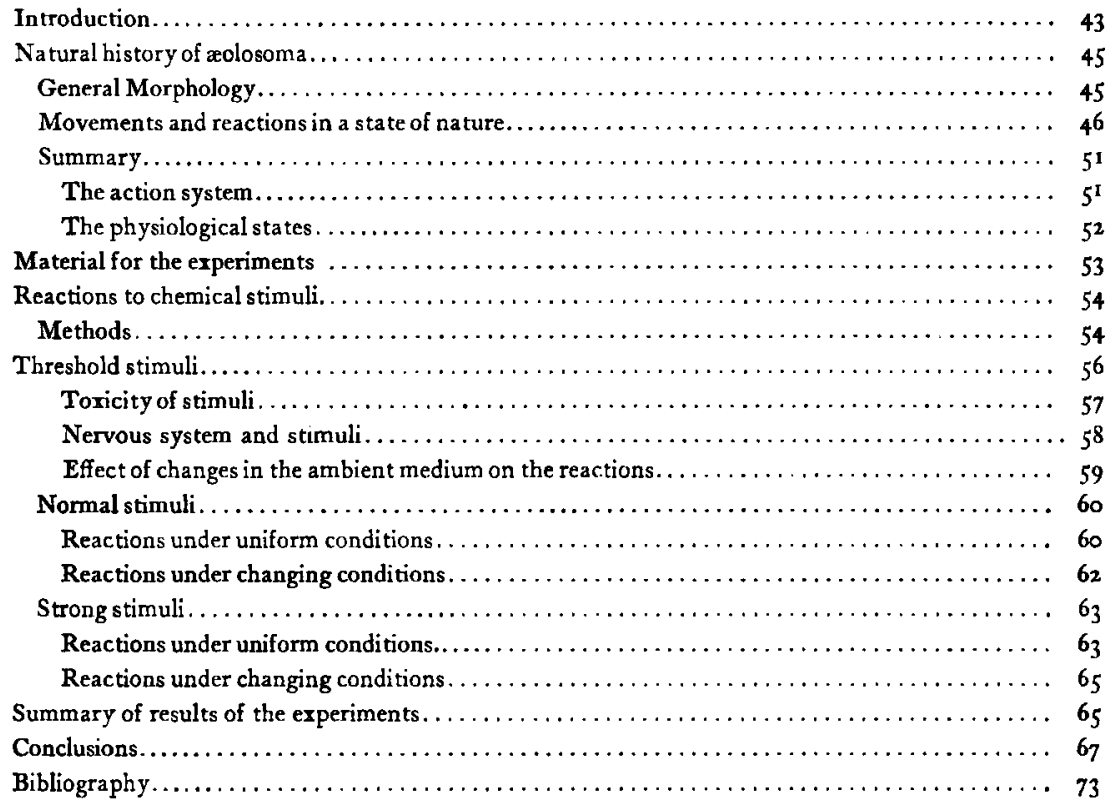

\section{INTRODUCTION}

The object of this paper is to consider the movements and reactions of Æolosoma under definite conditions of control, as a contribution leading toward an analysis of the nature of its behavior.

Æolosoma is able to move about freely in the ambient medium. The energy which finds expression in the performance of these

The Journal of Experimental. Zoölogy, vol. vill, No. I. 
movements, for the most part at least, is set free by the rearrangement of certain chemical aggregates within the animal itself. These in ternal changes which find expression in external movement are a fundamental part of the animal economy. They tend to restore or maintain a certain physiological equilibrium which is essential to its well being.

On the other hand, the ultimate source of the energy which gives rise to these movements comes to the animal through external media. As the animal moves about it is constantly coming in contact with other supplies of energy which have their play in its environment, and there immediately results a mutual reaction between the animal economy and the external supply of energy or "stimulus" thus encountered. The form of the reaction that may be exhibited upon such a contact depends both upon the morphological and physiological organization of the animal, and also upon the sort of stuff that may house the external energy. If this energy be in the form of food particles, for instanre, it may be readily appropriated through the various channels of ingestion and assimilation. If it be such as to disturb the internal processes, other and varied movements may result. The sum total of all the movemen ts exhibited by Æolosoma in a given time, in response to a changing environment, we designate as its behavior.

The problem of behavior from this point of view naturally hinges upon the interpretation of the relations which exist between the external stimulus and the concomitant reaction of the animal.

As an in troduction to this subject we will first consider themorphological basis of the behavior of Æolosoma; its movements and reactions in a state of nature; and finally physiological effects produced through physical changes in its environment. We will then investiga te the movements and reactions of Æolosoma under the control of definite chemical stimulations associated with certain changes in its environments as suggested by these observations on its natural history.

I wish to express my deep obligation to Prof. H. S. Jennings, who suggested this problem to me, and for his kind assistance in 
outlining a general method of procedure; to Profs. E. G. Conkin and J. Percy Moore for many valuable hints and corrections.

\section{NATURAL HISTORY}

Only very brief references to the natural history of Æolosoma may be found in the literature. Some of these will be noted in passing. No careful investigation into its behavior has been made.

\section{General Morphology}

Æolosoma is the only genus thus far described of the Oligochatan family, Eolosomidæ (Aphanoneura, Vedjovsky). It abounds in fresh water ponds and streams throughout the equatorial and neo-arctic regions A schematic drawing of the anima lappears in Fig. I. The different species vary in length from about $1 \mathrm{~mm}$.

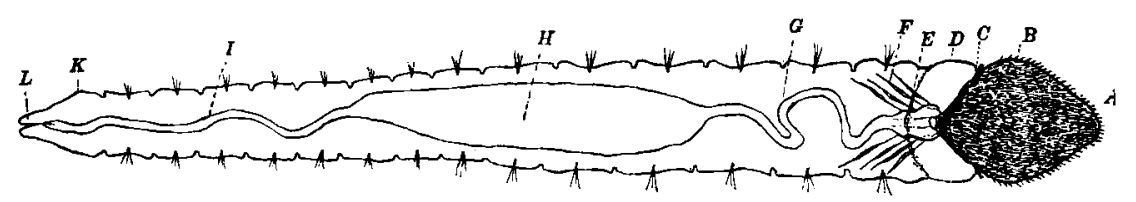

Fig. I. Ventral View of Æolosoma.

$\begin{array}{ll}\text { A } & \text { Sensory hairs } \\ B & \text { Prostomium } \\ C & \text { Buccal cirri } \\ D & \text { Peristomium }\end{array}$

$\begin{array}{llll}E & \text { Pharynx } & I & \text { Intestine } \\ F & \text { Muscle fibers } & K & \text { Caudal segment } \\ G & \text { Oesophagus } & L & \text { Papillæ } \\ H & \text { Stomach } & & \end{array}$

(A. qua ternarium) to about to $\mathrm{mm}$. (A. tenebrarum). The segments, expressed chiefly in epidermal structures, are from 5 to $\mathrm{I} 5$ or more in number. The brain, or cerebral ganglia, and the ventral nerve cord, are noteworthy in that they are buried in the epidermis (Vedjovsky '84). Each segment, with the exception of the head segment, and the budding zones, bears four bundles of setæ. The head segment bears a prominent flexible upper lip, or prostomium, which is ciliated on the under side. The prostomium is thin dorsoventrally, and is concave on the under side, making it somewhat spoonshaped. Circling about the tip of the prostomium project little spines or hairs, which are connected 
with sensory hairs lying on the inner side of the epidermis (Brace 'or). At its base the lateral edges of the prostomium fold into the buccal cavity. The ridge thus formed about the mouth possesses larger cilia than those present on other parts of the prostomium and the beat is correspondingly slower. Surrounding the mouth from the rear and running forward and upward, so as to partially overlap the rear lateral edges of the prostomium, is a a prominent under lip or peristomium. This lip may be so extended that it practically reaches the size of the prostomium, or so far withdrawn that it becomes almost invisible. It is notcilia ted The pharynx is a pear shaped organ and very muscular. It is attached to the body wall, caudad, by a series of muscle fibers. The anal segment has two papillæ at its tip, similar in shape and function to the toes of a rotifer. These papillæ seem to have been overlooked in previous observations on the structure of Æolosoma.

There are two layers of muscle fibers, one circular and one longitudinal, lying close to the inner side of the epidermis throughout the body segments. These muscle fibers are capable of enormous contraction and extension. Within the epidermis are numerous gland cells, some of which secrete mucus, while others secrete an oily substance which is scattered in characteristic "globules" throughout the epidermis. There is a thin semitransparent membrane forming the outer layer of the epidermis, and but loosely connected with the other epidermal aggregates.

Æolosoma is hermaphroditic. It also reproduces by the for.mation of zooids in a way similar to that of Stenostoma. I have never found any specimens that were sexuallymature. They have been observed, however, by D'Udekem ('62), Maggi ('65), Stolc ('89), and Nelson ('o6).

\section{Movements and Reactions in a State of Nature}

The food of Æolosoma consists largely of bacteria, diatoms, unicellular algx, and the soft mesophyll tissues of decaying leaves. When feeding the pharynx is generally progruded so as to come in contact with the substratum. The peristomium is also con- 
siderably extended and spread out on either side. The prostomium is spread out and elevated above the plane of the pharynx and peristomium. The pharynx sucks in the alga, bacteria, etc., assisted by the beat of the large cilia or cirri of the buccal cavity. When larger pieces of food are to be swallowed the prostomium and peristomium may be used as lips to envelop the substance to be ingested.

As an aid in securing foor the small cilia of the peristomium bea $t$ incessantly from before backwards, drawing currents of water from in front of the animal and washing them against the cirri of the buccal cavity. By testing these currents with fine india ink granules, it was noted that, in the case of a large A. tenebrarum, the currents began fully $4 \mathrm{~mm}$. anterior to the animal, were drawn past the sensory hairs in to the buccal cavity, then were caught and turned to either side by the extended peristomium.

These currents serve a twofold function. They carry particles of food material in to the region of the mouth, and also enable the animal, by means of sensory hairs, to test the media in to which it is moving. These cilia always beat in the one direction. As the animal moves along, the anterior segments of the body are shifted about in all directions by muscular activety. The head is also advanced and withdrawn successively. With these movements are seen various foldings or puckerings of the prostomium in which the little sensory bristles seem alternately to be covered over and then extended through the loose enfolding membrane. These associated movements are designated as the "exploring reaction." Similar movements on the part of the flat-worm, were called "feeling movements" by Pearl ('O3). At the suggestion of Dr. Jennings we have decided to classify these phenomena as "exploring reactions" as being less subjective and more appropriate in this particular field.

When approaching an unfavorable locality the "exploring" reaction becomes more pronounced, and is usually followed by a quick dart of the head backward and its extension in another direction. These darting movements always follow when the prostomium first comes in contact with any solid substance, or even with the surface film when crawling up the sides of the jar. 
If the object is not harmful the prostomium may be returned and thus touch the object two or three times until a certain "familiarity" is established. The animal then moves over about the object without further retardation. If the object should be injurious the backward move is vigorous, the head is thrust energetically in another direction, and a general movement away from the scene of contact is made. Sometimes the avoiding movement is so energetic that the dart backward and toward one side are practically simultaneous. In this case there is usually a compensa tory movement of the posterior segments in the opposite direction from that of the prostomium. At other times the action of the head may be entirely reversed by the violence of the movement and the animal will glide directly away from the unfavorable region. This movement is well illustrated when the prostomium comes in contact with one of the tentacles of a hydra.

The locomotor movements of Æolosoma while feeding are of a slow crawling nature. The beat of the cilia under the prostomium seem to play no part in them. Progress is made by means of successive alternate contraction and extension of the muscles of the body segments. In this way the $\mathbb{E}$.olosoma may move backward or forward. In the more rapid of these movements the pharynx and papillæ are alternately stuck to the sub-stratum while the other end is advanced or retracted. This movement may be so vigorous as to resemble the looping of a "measuring" worm.

There is generally associated with the feeding reaction a certain peristaltic movement of the body wall which is entirely independent of the movements of the digestive tract. The wave begins in the region of the pharynx and runs backward to the end, slightly elevating the several bundles of setæ as it passes through them. There is no evident shortening or elongation of the body during the process. The waves follow each other in rhythmical succession at brief in tervals. They may vary in size within rather wide limits. They are more vigorous about the time of the excision of a zooid from the parent. As constriction proceeds there is a noticeable "twitch" as the peristaltic wave passes from the parent to the zooid owing to the imperfect muscular connection 
between the two. It is during one of these twitches that separation is finally affected.

If the food becomes scarce in the immediate neighborhood Æolosoma may glide or swim to other regions in a way similar to the gliding movement of a triclad. In this case, the cilia under the prostomium are the only organs of propulsion. The body is somewhat extended and straight. The peristomium is withdrawn so as to be practically invisible. The cilia under the prostomium seemingly beat more rapidly than before and propel the animal forward. The setæ are turned to a sharp angle caudad. Movement is always forward and may attain a speed of $5 \mathrm{~mm}$. or more per second. All changes in directions are made by rotation of the head by exercise of the muscles of the pharyngeal region. When Æolosoma settles down after gliding or swimming the posterior segments are generally the first to come in contact with the substratum. Swimming in the open may also be stopped by a quick forward thrust of the setx. This may be vigorous enough to stop all forward progress or to even throw the animal slightly backward.

When Æolosoma comes to rest where currents of water are flowing, its position is maintained by gripping the substratum with the pharynx in a way similar to the suction disc of a leech, as noted by Beddard ('88), or more generally, by sticking to it by means of the caudal papillæ. When feeding, under such conditions, the papillæ only are used, changes in position being made by looping.

The Æolosoma show a great tendency to burrow in the ooze at the bottom of the jar. The prostomium is narrowed laterally and extended somewhat in front and then thrust downward in to the sediment. Progress is made by means of a rapid spiral twisting movement of the body.

In the performance of all these movements the animals secrete considerable mucus. The mucus entangles large numbers of bacteria and algx which are caught up as the animal moves about. For this reason the Tolosomea will frequently twist about and browse over the mucus flim surrounding the major part of the body, or apparently feed anew on old excreta. They are attracted 
to the mucus tracts and excretory masses more largely when the food supply is scarce. Under such conditions, when one Folosoma comes in contact with another the "feeding reactions" are mutually exhibited. They also get more or less stuck together by the adhesive mucus. If several get stuck together in this way the difficulties of separation become serious. This leads to what has been termed a "grouping" of Æolosoma.

The secretion of mucus may be also of protective significance. An Æolosom a was seized near the middle segments by one of the tentacles of an hydra. Immediately there was a violent end to end contraction of the body wall, in which large quantities of mucus and numerous oil globules were extruded. This stuff seemed to thicken considerably upon contact with the water. In a few moments the Æolosoma was able to squirm away with a spiral stretching movement leaving the mucus and globules in the grasp of the hydra. This heavy extrusion of mucus and globules was probably stimulated by the stinging cells of the hydra, as similar reactions are readily obtained with strong acid or alkali stimulations. These phenomena closely resemble the discharge of trichocysts by paramœcia under chemical stimulations (Massart 'OI); or when attacked by Didinium (Mast 'o9). Both of these authors assume that the trichocysts function as organs of defense.

Æolosoma come out more actively for food during the night. Many may be seen in the early hours of the morning feeding about the sides of the jar. On a bright day, when the jar is not protected from thelight, they gradually seek refuge among the debris at the bottom of the jar. If the jar then be carefully covered over, in a few hours they come out of their hiding place and feed as before. When they are put in to a clear glass dish on the stage of the microscope and bright light turned upon them from beneath they move about so actively that it is most difficult to observe them carefully. If a blue glass is placed beneath them and the source of light their movements are noticeably accentuated. Ultra-violet light ( 2275$)$ destroys them in a few moments. Little change in their behavior, if any, was induced by red light. If a number of $Æ$ losoma are placed in a clear glass dish and subjected 
to very bright daylight for several days, the number and size of the oil globules are considerably increased. Budding and fission. however, show a marked retardation. On the other hand, if they are kept in the dark for the same leng th of time, the appearance of the oil globules undergoes no perceptible change, but the number of budding zooids will be noticeably large.

The activity of Æolosoma also varies with changes of temperature. When the water is cold their movements are correspondingly sluggish. As the temperature is raised the animal becomes increasingly more active until Ehrenberg's description as "extremely agile" becomes peculiarly fitting. The same animals will pass through all stages of relative activity from the early hours of the morning when the water is cool to the mid-afternoon when the temperature is raised by the warmth of the day.

These variations in activity are correlated with changes in the processes of constructive metabolism. If the animals are kept in cold water they feed very slowly and evidence of reproduction practically disappears. Just the reverse is true when the water is kept warm for some days.

Æolosoma seems to require certain periods of rest. The resting stage may be observed more generally when the light is subdued, and the water is cool. The only movement in evidence at such times is the gentle waving of the setæ. The animals lie somewhat extended and approximately straight. If left undisturbed they may lie in this position for several hours at a time.

\section{Summary}

The Action System

The daily life of Æolosoma exhibits, as has just been shown, certain movements which we may call the "action system" of the animal (Jennings' ${ }^{\circ} 4$ ).

Some of these are primarily concerned in the quest of, and the ingestion of food.

I The beat of the cilia under the prostomium which may draw sample currents of water past the sensory hairs, or may propel the animal in gliding or swimming. 
2 The "exploring" movements, which consist of little side thrusts of the head in various directions associa ted with a puckering of the prostomium.

3 The crawling movement, in which progress is made only by muscular contraction and extension. Progress may be assisted by alternate holding to the substratum by means of the pharynx and caudal papillie.

4. The feeding reaction, which consists of the extrusion of the pharynx, and the swallowing of food particles.

Other movements are protective.

I The a voiding movements, which consists of a backward dart of the head and its projection in another direction.

2 A vigorous contraction of the body segments which squeezes out many gland cells, mucus and globules.

3 Burrowing in the sediment.

4 Holding to substratum by means of pharynx or caudal papillæ.

More or less associa ted with all of the above movemen ts are peristaltic waves and the constriction of zooids.

\section{The Physiological States}

The emphasis with which these movements may find expression and their coördination in the animal economy varies widely under changing conditions. These changing conditions in the ambient medium have an immediate effect on the equilibrium of the in ternal sta tes of the animal. These physiological states, as associated with changes in external conditions, for our present purpose, may be grouped under the following categories:

I State of Relaxation. This state is peculiar to a cool environment when the light is subdued.

2 State of Normal Activity. This embraces the phenomena of the feeding and exploring reactions, the crawling and gliding movements. It marks the time when the processes of metabolism and anabolism are in balance.

3 State of $\mathcal{T}$ ension. This marks the period when destructive forces are in ascendency. The movements are energetic and 
exhausting. Readjustment of equilibrium through movement approaches a minimum. May be produced by high temperature or excessive light.

\section{MATERIAL FOR EXPERIMENTS}

Two species of Æolosoma were used in the course of these experiments. One, probably A. quaternarium, Ehrenberg, was found in great abundance in old paramœcium cultures. The basis of these cultures usually consisted of partially decayed leaves and grass from near the shore of a small pond in the Botanical Gardens of the University of Pennsylvania. The fact that the materials from which these cultures arose was gathered when dry suggests either that the Eolosoma come from encysted animals or from eggs. I have not been able to discover whether they come from one or both. The life history of this species seems to undergo periodic changes (Ved jovsky, I892), quite different from that of A. tenebrarum. The cultures were always several weeks old before the Folosoma appeared. When first discovered they always were full grown with the fission zone of budding zooids well marked in numberless individuals. From these same cultures after extensive proliferation for two or three months, the whole colnny of Folosoma sometimes disappeared in the course of a single night. I examined the sides of the jar and much of the débris at the bottom but could not find anything that was suggestive of the causes or results of this phenomenon. Beddard ('92) had the same experience but later discovered the encysted Folosoma. He attributes the encystment to the approach of cold weather. My cultures evidently suffered from the introduction of some pathogenic conditions which destroyed them.

The other species, probably A. tenebrarum (Vedjovsky) was gathered in large quantities from the slime on loose stones along the shores of the Schuylkill River, just below Flat Rock Dam, a few miles north of Philadelphia.

These species, with a number of slime covered stones were preserved indefinitely in 8 inch battery jars. Other cultures of A. tenebrarum were frequently secured by placing old water hya- 
cinths in battery jars filled with fresh water. In a few days large numbers of the Æolosoma might be observed during the early hours of the day, crawling about the sides of the jars.

There were a number of suggestive differences noted between these two species in their reactions to changes in the relative amount of light, moisture, and temperature pervading the ambient medium. These phenomena will be considered in another paper. At present our purpose is to work out the main features of the action system as shown in both species under the influence of external stimuli. We examine first the reactions to chemicals for the reason that with them it is easy to control and stimula te all the movements normally exhibited in the action system, and thus to observe the mechanism of the response.

REACTIONS TO CHEMICAL STIMUI.I

\section{Methods}

A graded series of experiments was made with the following chemicals:

I Mineral acids: $\mathrm{HCL}, \mathrm{H}_{2} \mathrm{SO}_{4}, \mathrm{HNO}_{3}$

2 Organic acids: $\mathrm{HC}_{2} \mathrm{H}_{3} \mathrm{O}_{2}$ (acetic), $\mathrm{H}_{2} \mathrm{C}_{2} \mathrm{O}_{4}$ (oxalic), $\mathrm{H}_{3} \mathrm{C}_{8} \mathrm{H}_{5} \mathrm{O}_{6}$ (citric).

3 Hydrates: $\mathrm{KOH}, \mathrm{NaOH}$.

4 Carbonates: $\mathrm{K}_{2} \mathrm{CO}_{3}, \mathrm{Na}_{2} \mathrm{CO}_{3}$.

5 Halides: $\mathrm{KCl}, \mathrm{KBr}, \mathrm{NaCl}, \mathrm{NaBr}$.

6 Sulphates: $\mathrm{FeSO}_{4}, \mathrm{CuSO}_{4}, \mathrm{ZnSO}_{4}$.

The acids and alkalies were titrated to standard normal solutions $(n)$. The salts were prepared in gram-molecular solutions $(m)$. The first series of experiments were made by allowing the chemical stimulus to flow toward the animal through a fine capillary pipette, the conducting tube of which had an inside diameter of $0.3 \mathrm{~mm}$. the bulb holding about $\frac{1}{2} \mathrm{cc}$. of the fluid, with an air tube a trifle larger than the conducting tube. The orifice of the conducting tube was placed about $\frac{1}{2} \mathrm{~mm}$. from the part to be stimulated. Localized applications of the chemical were thus made at the head segment, at the caudal segment, and finally upon the middle segment of the body. 
A control with distilled water prereded each experiment. I found that the distilled water had to be particularly pure or of itself it would afford a definite stimulus. The water finally used was so prepared that the Eolosoma were practically indifferent to its presence in the control experiment. There is always a slight rheotactic stimulus to which Æolosoma will respond if the flow from the capillary tube is rapid enough. I found, however, that with the tube above mentioned there would be no characteristic response under the conditions stated. The chemicals were diluted in distilled water previously tested in the control.

In order to obviate, as far as possible, differences in reaction occasioned by such changes in the environmental conditions as variations in temperature and light would produce, the major experiments of this paper were performed during the early hours of the day, the culture jars being well protected from the light during the hours preceding, and the room shaded during the course of experiments. The temperature of the cultures and of the materials used was maintained very close to $15^{\circ} \mathrm{C}$. Even with these precautions there is considerable variation in the behavior of different individuals preventing a precise quantitative test of stimuli. The qualita tive reactions of many individuals, however, show a close correlation with various strengths of stimuli, so that we are able to analyze them with reasonable certainty.

In the course of these investigations several hundred experiments were made with each reagent. Only those, however, that have a direct bearing on our problem will be reported this time. I have therefore arbitrarily assorted the stimuli used in to three main groups as shown in Table I.

TABLE I

\begin{tabular}{|c|c|c|c|}
\hline & & & \\
\hline Mineral acids. & $\begin{array}{l}\text { Threshold } \\
\text { c. } x / 3000\end{array}$ & $\begin{array}{l}\text { Normal } \\
\text { c. } N / \text { I0 }\end{array}$ & $\begin{array}{c}\text { Strong } \\
\text { c. } N / 3 \infty\end{array}$ \\
\hline Organic acids. & c. $\mathrm{N} / 2000$ & c. $\mathrm{N} / 6 \infty 0$ & c. $s / 2 \infty$ \\
\hline Hydrates.... & c. $N / 1500$ & c. $N / 800$ & c. $\mathbf{N} / 200$ \\
\hline Carbonates.. & C. $N / 1200$ & c. $N / 5 \infty$ & c. $N / 200$ \\
\hline Chlorides.. & c. $M / 80$ & c. $M / 4^{\circ}$ & c. $M / 20$ \\
\hline Bromides.... & c. $\mathrm{M} / \mathrm{5}^{\circ}$ & c. $\mathrm{M} / 30$ & c. $\mathrm{M} / \mathrm{IO}$ \\
\hline 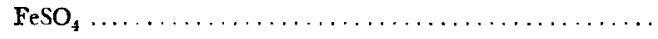 & c. $M / 10000$ & c. $M / 8 \infty$ & c. $M / 400$ \\
\hline 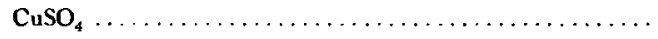 & c. $M / 80000$ & c. $\mathrm{s} / 20000$ & c. $M / 1000$ \\
\hline $\mathrm{ZnSO}_{4} \ldots \ldots \ldots \ldots \ldots \ldots \ldots \ldots \ldots \ldots \ldots \ldots \ldots \ldots$ & c. $\mathrm{M} / 80000$ & c. $v / 20000$ & c. $\mathrm{m} / 2000$ \\
\hline
\end{tabular}


Under threshold stimuli are grouped those solutions which lie at the threshold of physiological discrimination. They represent the weakest solutions which, under the conditions above stated, will interrupt the physiological poise of the animal at the moment of impact, enough to produce a visible reaction. They produce this effect only when in troduced to the sensory hairs of the prostomium.

Under normal stimuli are grouped those solutions which will stimula te a characteristic reaction when introduced to any part of the body. They are not strong enough, however, to inflict any permanent injurv to the tissues of the body. The movements occasioned by those reactions are seemingly normal. They have that easy flexibility which the animal daily exhibits under conditions fa vorable to its existence.

Under strong stimuli are grouped those solutions which force a powerful reflex movement on the part of the organism. The reactions are energetic and exhausting. They quickly develop fatigue, and upon repetition may prove fatal.

The concentration of the above solutions in each respective group is not exclusive. They vary rapidly toward or from each other under changing conditions. In our experiments, however, they were typical stimuli of the reactions now to be described.

\section{The "Threshold" Stimuli}

The threshold reactions were tested from a point directly in front of the prostomium and then lateral to the same.

Mineral Acids. When stimulated from in front there is a slight wrinkling movement of the prostomium, during which the head is advanced toward the pipette, then withdrawn and moved about with the characteristic exploring movements. In the case of $\mathrm{H}_{2} \mathrm{SO}_{4}$ these movements were repea ted more vigorously than with the others, with the result that the head was soon brought in to close contact with the pipette. There then followed a quick reflex away from the source of stimulus. With a lateral application the head is rotated toward the source of stimulation through 
the pipette, after which the exploring reactions were exhibited as before. The animal then moves away at varying angles.

Organic Acıds. The reactions were similar to the above. Acetic acid always seemed further to stimulate an erection of the more anterior setæ. The reactions to citric acid were similar to those with sulphuric acid. The puckering of the prostomium was more marked with oxalic acid.

Hydrates. It is very difficult to get a characteristic reaction with the hydrates. The animals invariably turn away from the source of stimulation without giving marked evidence of the exploring reaction. If the stimulus is repeated several times they curl up and give no further movement. When left alone they slowly resume normal activities.

Carbonates. The animal gives a positive reaction in every case. The exploring movements were well marked, and were associated with contractions of the pharynx as though feeding.

Halides. The head is swayed slowly from side to side with a rythmical motion. The peristaltic movements are markedly accentuated by both the $\mathrm{Na}$ and the $\mathrm{K}$ solutions. The exploring reaction was not in evidence. The animals make no effort to move toward or away from the pipette.

Sulphates. There is a positive reaction to $\mathrm{FeSO}_{4}$ in every case, associated with the normal exploring movements of the anterior segments. $\mathrm{CuSO}_{4}$ develops in Æolosoma reactions practically identical with those of the mineral acids. With $\mathrm{ZnSO}_{4}$ exploring reactions are very slow, but the puckering of the prostomium is more strongly marked.

In all of these experiments, with the exception of the halides and hydrates, it must be noted, that in the stimulations lateral to the prostomium the animal first turns its head toward the side which is stimulated. The normal exploring reactions were then exhibited with the result that the animal finally moved toward or away from the field of stimulation.

\section{Toxicity of Stimuli}

Were these movements correlated with the relative toxicity of the elements used? To test this a number of Folosoma were 
placed in the several threshold solutions. It is obvious that immersion in these solutions presents to the animal membranes a more concentrated form of the chemical than they experienced under a localized impingement introduced through the pipette. After noting carefully the flow of the current from the pipette to the animal, which can readily be seen under the microscope, however, I am inclined to believe that differences in concentration due to diffusion are not significant. The ratio between the various stimuli will hold in either case.

When placed in $\mathrm{N} / 3000$ mineral acid solution the animals soon developed increased peristalsis and exhibited various twisting and stretching movements. They seemed to be normal on the following day. In $\mathbf{N} / 2000$ these movements were accentuated. The animals died within a day or two. A similar experience followed the use of $\mathrm{N} / 2000$ and $\mathrm{N} / \mathrm{r} 000$ of the organic acids. N/1500 of the hydrates was fatal in four or five days. The Æolosoma, however, seem to be able to live indefinitely in $\mathrm{N} / \mathrm{I} 200$ carbonate solution. The threshold solutions of the halides were fatal in a day or two. $\mathrm{N} / 10,000 \mathrm{FeSO}_{4}$ was not fatal in four or five days. N/5000 was fatal in a few hours. The threshold stimulations of zinc and copper sulphates are not injurious to the animal. N/40000 of the zinc solutions, however, is fatal within 24 hours, that of the copper not within two days.

The evidence furnished by these facts in not very consistent. From the point of view of a positive or a negative reaction to a localized stimulus, however, we conclude that the reactions of Folosoma to the threshold solutions of these chemicals may be correlated with their rela tive toxicity.

\section{Nervous System and the Stimuli}

Does the presence of a nervous system play a significant part in threshold reactions? To this test two series of experiments were used. In the first case the head segment was severed from the rest of the body with a pair of sharp needles. The cut surface bealed over in a very short time. After several hours the above threshold experiments were introduced with negative results. 
On the following day, when the new prostomium seemed tolerably well de veloped, there was still no response. About two days la ter, when the sensory hairs could be distinguished, the great majority of the animals reacted as normal.

The next experiment was made by tapping gently with a fine bristle that part of the epidermis in which the cerebral ganglia lie buried. The animal wriggles energetically at first, but upon repetition the nervous system suffers paralysis or fatigue, and the animal soon curls up and refuses further movement. After the Æolosoma had begun to relax, the threshold experiments were tried and received no response. In many cases it was nearly an hour before the exploring reactions could thus be stimulated. In all of these cases, very soon after the introduction of the mechanical inhibitions, the stronger solu tions, here called " normal stimuli" would develop their characteristic reactions.

These data suggest that any interference with the in tegrity of the nervous system of $Æ$ olosoma, will raise the threshold of chemical stimulation.

\section{Effect of Changes in the Ambient Medium on the Reactions}

Changes in temperature were made by placing the culture dish in a water bath which is warmed or cooled to the required temperature and so maintained for several hours. The experimental media were also correspondingly treated. For very bright daylight the animals were subjected to the light coming from above and also reflected upward from beneath. For much of the time direct daylight was used.

I If the temperature of the water is lowered to about $10^{\circ} \mathrm{C}$. no characteristic response can be developed by means of these threshold solutions.

2 If the temperature of the water is raised to $20^{\circ} \mathrm{C}$. the reactions to the above threshold solutions are very similar to those recorded later under the so-called "normal stimuli." The threshhold of chemical discrimination is raised to solutions more than twice as dilute as the above.

3 If the animals are subjected to bright light for several hours 
and then treated with these weak solutions the results are similar to those produced when they are subjected to a raise in temperature, although the threshold varies within much narrower limits.

\section{The "Normal" Stimuli}

\section{Reactions Under Uniform Conditions}

Mineral Acids. When solutions of this strength are applied to the tip of the prostomium there is first evident a wrinkling of the prostomium and an erection of the setæ of the anterior segments. The head is then drawn backwards and quickly turned toward one side. Sometimes the negative reaction may be so marked as to reverse the general direction of its movement prior to stimulation. As a rule the animals move at varying angles away from the field of stimulation. When applied laterally to the prostomium the head segment is frequently turned toward the pipette before the negative reaction is expressed. Stimulation at the posterior

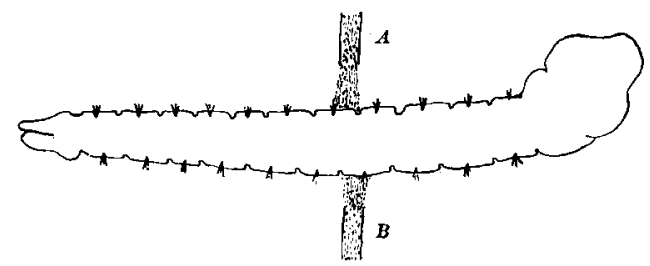

Fig. 2

papillæ causes the posterior segments to con tract, thus pulling the papillx forward. Sonetimes the caudal segment is swung away from the stimulus. When the chemical is first applied at the caudal segment there is no change in the attitude or movement of the anterior segments. Repeated stimulation may cause rapid crawling forward.

When the chemical is applied to the middle segments of the body the ventral muscles always contract more than the dorsal. The resultant movements are determined by the attitude of the animal at the moment of stimulation (Fig. 2). If this attitude is 
like that shown in Fig. 2A, the first contraction throws the head nearer to the stimulus. This is followed by a reverse movement in which the animal moves away. If as in Fig. $2 \mathrm{~B}$, the first contraction turns the animal away from the stimulus and movement is continued in that direction. This principle holds true regardless of the direction from which the pipette may throw the impinging chemical upon the body wall,-- whether it be directed toward either side, dorsally or ventrally. The "secondary reflexes"those movements which immediately follow this first reflex--are such as to move the animal away from the field of stimulation.

Organic Acids and Hydrates. Reactions to these solutions were similar to those developed by the mineral acids. With the hydrates, however, it was noticed that many individuals would stop in their onward rush from the stimulus, would curl up in crescent shape, and seemingly rub the prostomium to and fro with a lateral swing on the substratum. When placed in a culture jar after the experiment they invariably burrowed in to the ooze at the bottom of the jar.

Carbonates. There are quick negative reactions to the carbonates at both head and caudal segments, though the animal makes but little effort to get away from the stimulus. When stimulated at the side so that the ventral contraction throws the head nearer to the pipette, in few cases was there any evidence of a reverse movement. Vigorous puckerings of the prostomium were noticeable; a few writhing movements were made; and then the animal would usually lie dormant until the effect of the stimulus passed away.

Halides. The initial reaction to the halides was like that to the acids. These were invariably followed by so marked an increase in the peristaltic waves, however, that progressive movements were inhibited for some time. The $\mathrm{K}$ solutions stimulated increased peristalsis much more vigorously and quickly than the $\mathrm{Na}$ solutions.

Sulphates. When $\mathrm{FeSO}_{4}$ is introduced directly in front of the animal, the head is slowly waved to and fro, laterally, several times, after which the Æolosoma curls up with a twisting motion, and makes no effort to move away. When in troduced la terally the 
head is first turned toward the pipette before expressing these movements. There is a large increase in the amount of mucus secreted. When stimulated at the posterior papilla, the caudal segments are slowly contracted and swing toward either side. Some seconds after stimulation the head segment shows a marked increase in the exploring reaction. When applied to the lateral segments the animal first curls as usual, then twists about with increasing energy but with no locomotor results. The reactions to $\mathrm{CuSO}_{4}$ were similar to those with the mineral acids. In the case of $\mathrm{ZnSO}_{4}$ the great majority moved away from the stimulus with a spiral twisting reaction, al terna ting this reaction every few seconds by curling up and vigorously rubbing the prostomium on the substratum. When put back in to a culture dish they immediately burrowed in to the ooze at the bottom of the jar.

In all of the above reactions, which were followed by locomotion there was noticeable a marked increase in the vigor of the characteristic "exploring movements." The end result was that the animal followed a decidedly zig-zag course.

\section{Reactions Under Changing Conditions}

a. The head is severed from the body by a cut through the region of the osophagus. Within a few hours the anterior segment of the body will respond to the above stimuli of normal strength in a way characteristic of the normal exploring reaction. Lateral applica tions may cause the dorso-ventral contractions but they are not followed by the reverse movements that are noted under normal conditions.

$b$. The animal is physiologically depressed by tapping the cerebral ganglia as described under threshold stimuli. The reactions to the various chemicals under these conditions do not exhibit the usually distinc tly nega tive quality but resemble more closely those given above under $\mathrm{FeSO}_{4}$.

c. The tempera ture is gradually lowered to about $10^{\circ} \mathrm{C}$. It is difficult to get any characteristic reactions except at the prostomium, and these correspond closely to the threshold reactions at $15^{\circ} \mathrm{C}$. The lack of any marked reaction when the body segments 
are impinged upon by the chemical is evidently due to the formation of a protecting membrane or the thickening or hardening of the mucus film which surrounds the body, under the stimulus of the cold.

$d$. The temperature is raised to about $20^{\circ} \mathrm{C}$. The reactions to these solutions are quick, almost violent. When the chemical is applied directly in front of the prostomium the reaction invariably brings about a complete reversal of the line of movement. When applied la terally to the prostomium the reaction is directly away from the pipette without preliminary testing movement. When applied to the middle segments of the body the contraction is so vigorous that in many cases oil globules and gland cells are squeezed out in the process. In the case of the alkalies there was noticed the beautifully rich magenta coloring observed by Beddard ('89). Application at the posterior papillie readily stimulated the forward crawling movement even to "looping."

$e$. The animals were subjected to very bright daylight for several hours.

With the wa ter at a temperature of $10^{\circ} \mathrm{C}$. many of the reactions were in accord with the original experiments at $15^{\circ} \mathrm{C}$. With the tempera ture main tained at $15^{\circ} \mathrm{C}$. the reactions were much more vigorous and largely resembled those expressed in response to the stronger solutions. Many of the contractions were vigorous enough to squeeze out oil globules and mucus cells. With the temperature raised to $20^{\circ} \mathrm{C}$. the reactions were vigorous and exhaustive, and in many cases proved fatal.

\section{The "Strong" Stimuli}

\section{Reactions Under Uniform Conditions}

Mincral Acids. When stimula ted at the tip of the prostomium there is a quick nega tive reaction which may reverse the direction of movement. Sometimes the head is thrown only part way toward the rear and the animal moves away at an angle. The progress of the stimulus can be noted. The prostomium is first bowed away from the stimulus; all the setæ are erected rigidl at 
right angles to the body, then a sudden turn is made away from the stimulus. With a lateral application to the prostomium the head is not turned toward the pipette before the negative reaction takes place. Application at the posterior papillæ stimulates a quick contraction of the posterior segments and a rapid crawling movement forward. Lateral body stimulation follows the same rules as under normal stimuli, only the reactions are far more energetic. Not infrequently the first contraction will throw out many oil globules, etc. Movement away in this case is through a spiral twisting reaction.

Organic acids were similar in effect to the mineral acids.

Alkalies. All reactions were in the shape of energetic contractions of the body, away from the stimulus when applied to the ends of the body, with the bulge towards the stimulus in response to the la teral exposure. The animals were powerless to make any further effort to leave the field of stimulation although they recover rapidly from the shock. The muscles of the body wall facing the pipette seem to be paralyzed by the chemical as that side seems passive in the movements that soon follow. These movements are an alternate con traction and extension of the muscles of the body wall opposite to the place of stimulation.

Halides. There is a prompt negative reaction when these are applied to the head and the animal is usually able to get away from the stimulus. This is not the case when the caudal end or side is stimulated. When stimula ted at the side the first contraction is followed by increasingly large peristaltic waves running from pharynx to papillæ, which effectively inhibit any locomotor movements. With the bromides at the papillæ, the papillæ are quickly stuck to the substratum while the anterior parts twist and writhe in all directions. With the chlorides a forward contraction may advance the animal a little, but it soon loses power of orientation and lies at the mercy of all sorts of muscular contraction and extension.

Sulphates. The reactions to $\mathrm{FeSO}_{4}$ were similar to those with the halides. $\mathrm{CuSO}_{4}$ and $\mathrm{ZnSO}_{4}$ had the same effect as the acid solu tions.

All of the chemical solutions under this category had the further 
effect of producing precocious excision of budding zooids. Many of these zooids were soimma ture that the budding zone was almost imperceptible, yet they were readily snipped off by the energy of the con traction, or through the agency of the accen tua ted peristalis. They usually survived the shock, and were able to swim about on the following day. In many cases where a repetition of the stimulus proved fatal to the parent stem, these prematurely excised zooids recovered.

\section{Reactions Under Changing Conditions}

With head segment removed all of the characteristic reflexes were given. I was able to stimulate the crawling movement by application of the chemicals at the papillæ. This was also true af ter the animal was depressed by tapping over the cerebral ganglia.

When the temperature of the water was lowered to $10^{\circ} \mathrm{C}$. the reactions took more the form of those given under normal stimuli. The animals endured repetition of the stimulus without fatal results. With the temperature raised to $20^{\circ} \mathrm{C}$. it was difficult to apply the stimulus to all without the reaction being so vigorous as to prove fatal. This could only be done when the animal was stimulated at the prostomium. In these cases the negative reaction is so vigorous, especially with the acid, the copper and zinc sulphate solutions, that the animal is thrown directly away from the source of stimulation, and far enough so as to be able to escape.

If the animals were subjected to very bright daylight before these experiments were made the solutions invariably proved fatal soon after the first application of the chemical. The influence of the light upon the tissues of the body is such that it increases the toxicity of these solutions if they are applied after the animal has been exposed to the light for a few hours.

\section{SUMMARY OF RESULTS OF THE EXPERIMFNTS}

These experiments show that every movement expressed by the action system of Æolosoma in its native environment may be reproduced under conditions of control through the agency of various chemical stimula tions. 
Results with "Threshold Stimuli" (chemicals very weak, see p. 56)

a Chemical stimulations of threshold intensity develop the normal exploring reaction in \#olosoma.

$b$ If the stimulus impinges laterally to the prostomium, there is a turning of the head segment toward the field of stimulation before the exploring movements are expressed.

$c$ After a brief exploring reaction the animal moves toward or away from the field of stimula tion-gives a "positive" or a "negative" reaction to the stimulus.

$d$ The movements expressed in these reactions vary within ra ther wide limits, and cannot be coördina ted with "lines of diffusion."

$e$ The aggregate of movements exhibited varies with changes in the chemicals used. The na ture of the stimulus is an important factor in determining the nature of reaction.

$f$ Any interference with the integrity of the nervous system raises the threshold of chemical discrimination.

$g$ The reactions to threshold stimuli may be loosely correlated with the relative toxicity of the chemical involved.

$h$ The threshold of chemical discrimination varies rapidly with changes in the physical nature of the environment.

Results with "Normal Stimuli" (chemicals moderately strong, see p. 60)

a Æolosoma may exhibit all of the movements comprised in the action system in response to chemical stimulation of this order.

$b$ There are no characteristic positive reactions to chemicals of this order.

$c$ Many of the negative reactions are directly away from the field of stimulation. The great majority of the nega tive reactions, however, are composed of decidedly random movements, which continue until the animal is freed of the stimulus.

$d$ There is a certain degree of individuality among the segments. The posterior segments may be made to give a definite 
reaction without any response being given by the anterior segments.

$e$ Different parts of the body are affected in different ways by the same stimulus. A given stimulus which may cause a well coördinated negative reaction if applied at the anterior segment, may inhibit coördinated movement if applied at the middle segments of the body.

$f$ Any interference with the integrity of the nervous system seriously interferes with the power of coördinated movement.

$g$ Physical changes in the environment, due to variations in the relative amount of light and heat pervading it, produce an effect upon the animal economy equivalent to the effect produced by different concen trations in the chemicals used in these experiments.

Results with Strong Stimuli (chemicals very strong. see p. 63)

a Reactions to chemicals of this order, when applied to the anterior end consist of a vigorous reflex movement which throws that end away from the field of stimulation. The an:mal may then exercise its powers of locomotion and escape.

$b$ When these chemicals are applied to any other part of the body the reflexes are of such a nature as to inhibit coördinated movement away from the stimulus.

$c$ Interference with the in tegrity of the nervous system does not seriously modify the type of reaction developed by these solutions.

$d$ The energy imparted to the animal by these chemicals may be directly accentuated by an increase in the relative amount of light or heat pervading the ambient medium.

$e$ The rela tive toxicity of these solutions depends largely upon the age of the part impinged, and also upon the physiological condition of the organism as a whole.

\section{CONCLUSIONS}

By means of the localized application of different chemicals with varying concentration we have stimulated in Æolosoma characteristic movements designated as the action system. This shows 
conclusively that chemotoxis plays a very significant part in the methods and processes of animal behavior. It shows, further, that under conditions of control one may approxima te the physiological states which underlie the movements an organism may exhibit in a state of nature. The various movements which we have stimulated artificially, are of the nature of reflexes, more or less complex. Many of these are so haphazard in their expression that they seem to be merely the spontaneous play of various a mounts of energy, released within the mechanism of the animal. On the other hand, some of these movements possess a certain element of precision or adaptation which is manifestly beneficial to the organism. They remove the organism from an injurious en vironment in the quickest possible way. One of the first problems in Animal Behavior is: How did these more adaptive reflexes arise in a state of nature? Our effort, therefore, will be to correlate the reflexes observed here under wider categories that will help to in terpret the action system of Æolosoma in a phylogenetic way. Before we suggest a solution of our problem, however, it is necessary to estimate carefully the modus operandi of the various reactions in volved.

In the case of the threshold reactions, when the stimulus impinged la terally upon the prostomium there followed a turning of the head segment toward the source of stimulation. Was this turning due to the asymmetrical impingement of the lines of diffusion, or to the electrolytic effect of moving ions upon the cell membranes of that side of the head? In some way both of these factors may have been involved. On the other hand it must be noted that although the animal turned toward the side which was stinulated, the angle in which the solution is projected toward the animal through the pipette mav vary within enormous limits without developing any variation in the side thrust of the reaction which immediately follows. The prostomium is turned toward that side which is first inpinged upon by the chemical, regardless of the direction from which that chemical may come. Again, after the initial exploring reaction has been expressed, with the exception of the positive reactions, all of the succeeding movements have no direct reference to the stimulus, its direction, or its source. 
The fact that only experiments with electrolytes are recorded here suggests an interesting problem from that point of view. Several hundred tests were made with the non-electroly tes-urea, cane sugar and glycerine,- - but with negative results. An effort is now being made to find a non-electrolyte that will stimulate a characteristic reaction, similar to any of the above. After these experiments are concluded, something further may be determined as to the role of electrolytes in this field. The fact that Pearl ('03) stimula ted a similar turning of the anterior part of the flatworm--equivalent to our exploring movement-by means of a light touch with a piece of wood, suggests that the secret of this reaction lies within the confines of the animal economy. We therefore, conclude, for the present, that the turning toward the stimulus in the case of Æolosoma, is due to a sense of chemical change; to a difference in intensity arising locally in the animal's environment. The movement was not an orientation.

Associated with this turning of the head the exploring movemen ts were expressed. The animal then moved toward the source of the chemical, exhibiting the feeding reaction, or away from the same by means of a slow crawling movement. The positive reactions were due to the fact that the weak solutions of the carbonates or iron sulphate stimulated certain internal changes akin to those induced by food particles. It is interesting to note that with a rise in the temperature of $5^{\circ} \mathrm{C}$, , or more, the animal uniformly responds negatively to these stimuli. The ability of these solutions to stimulate the feeding reaction is thus conditioned by the physiological sta te of the organism--by its previous in ternal reactions to external changes in its environment.

As the concentration of the various chemicals is increased, the reflexes become more and more distinctive. When the chemical is applied to the prostomium the reflex is always lateral-away from the impinging stimulus. This is usually a right angled turn in the case of "norma." stimuli. If the chemicals are much stronger than this grade, two facts are noticeable. In the first place, the reactions to prostominal stimulation are similar with all the chemicals. This is never the case with the weaker solutions. In the second place the axis of locomotion is directly reversed by 
the force of the stimulated reflex. As the chemical becomes more and more dangerous to the organism, the initial reflex, developed upon contact with the chemical, throws the animal ever further away from its influence. Is this reaction due to an increase in control of the movements of the animal by the lines of diffusion, or is it because the vigor of the reflex is proportiona te to the amount of energy liberated by the impinging stimulus? It seems most clear that the latter suggestion, only, can be adjusted to all the data here involved.

When the stronger stimulus is applied to the mid-sections of the body the reflexes are always ventral-irrespective of the exact locus of stimulation or the direction from which the chemical may come. This reflex tends to bring the head and caudal segments together. Sometimes this serves also to bring the prostomium nearer to the source of the stimulus. A counter reflex is then given, characteristic of the regular prostomial stimulation-reflex, which throws the anterior end away from the chemical, and if the stimulus is not too strong, the animal escapes.

The movements given in response to the different chemicals vary within verv wide limits. Each group of chemical stimulates reactions peculiar to themselves. Throughout the whole series, the ability of the animal mechanism to adjust itself to the impingement of a chemical upon the body wall (excepting the anterior segment) varies inversely as the strength of the chemical. This phenomenon is practically reversed in the case of prostomial stimulations. In these cases we have what we may call a prostomial reflex which is inherently nega tive and which serves a fundamentally regula tory function as the animal approaches a marked change in the environmental conditions.

These facts show conclusively that the problem of animal behavior must look for its solution in the physiological arrangement of the protoplasmic aggregates of the organism under investigation. So far as external stimuli are concerned we may conclude:

I. The sort of stimulus does not predetermine the reaction that will follow upon its impingement upon any part of the organism, although it may contribute a significant thrust to that reaction. 
2. The direction of the impinging stimulus-lines of force or of diffusion-affect the direction of the resulting reflex only incidentally. The morphology of the organism is the determining factor.

3. The in tensity of an impinging stimulus, or variations in its intensity, are significant in so far as they in terrupt the physiological poise of the organism involved. They may determine the vigor of, but not the sort of, reaction that may be expressed.

With these facts in mind, we may attempt an outline of the phylogenetic rise of the action system of Æolosoma in so far as it had been analyzed in this investigation. The basis of behavior rests upon the irritability of living protoplasm. A thoroughgoing in terpretation of this irritability is yet to be made; it is far beyond the range of our present experimental knowledge of protoplasm. This much we do know-irritability presupposes movement, and the use of movement formulates the quest of "beha vior." All of the movements potential to the protoplasmic aggregates, which we designate as an individual organism, are variously being expressed in the course of its life history (Jennings, 'o7). Some of these movements, in periods of stress, more readily than others, restore a certain physiological equilibrium, which is essen tial to the welfare of the organism, and which has been disturbed by the impingement of an external source of energy. Repetition of equivalent conditions of stimulation tends to reproduce such movements with increasing celerity, under the law of the readier resolution of the physiological states (Jennings, '04). By the process of natural selection these movements have been selected in to a system of characteristic reactions which we designate as the "action system." The rise of an action system has further played a profoundly morphogenetic rôle in the course of history of the organism (Bohn, 'o6). The animal is what it is because of past behavior.

This brief ou tline is esentially a recapitulation of the "trial and error" theory of the rise of behavior as ad voca ted by Jennings, or the selection of random movements as suggested by Holmes.

It attempts to balance the play of both internal and external forces in the rise of an individual animal economy. There 
are a number of in vestiga tors, however, who insist that for the sake of a more objective interpretation of the facts of behavior, more emphasis must be given to the orienting force of the external stimulus. Loeb ('88) observing that the heliotropism of many animals was singularly akin to similar phenomena exhibited by plants, suggested that the orienting function of lines of force (lines of diffusion, 1903) expressed by the equation $F(i)$, playing upon asymmetrical parts of an organism would account for the more precise movements exhibited concomitantly with the impingement of the stimulus in volved; the "positive" or "nega tive" reactions. Bohn in a series of excellent papers, and many other in vestigators, in this field, have shown conclusively that the directive force of any reaction which follows any sort of stimulation can be predicted only by a knowledge of the play of the previous forces acting upon the animal economy; by a careful estimate of the arrangement of characteristic internal aggregates which Jennings denominates as the physiological states. A more in tima te knowledge of these shif ting aggrega tes called physiological sta tes is certainly essential to any far-reaching interpretation of behavior. Our own data does not admit the classification of any of the movements of Folosoma as "orientation" in the tropic sense of the term. Loeb ('97) appreciating this difficulty, added another factor in behavior which he called Unterschiedsempfindlichkeit; represented by the formula $\mathrm{F} \frac{d i}{d t}$. This factor, however, throws the interpretation back to the physiological states, which are included in our analysis as given above.

More recently Walter ('o 7 ), probably representing the view of a number of investiga tors, defines the theory of "tropisms" as essentially based upon "an asymmetrical reaction to an asymmetrical stimlus." Granting to this view all that he would include we seriously question whether such a comprehensive statement can throw much light on the problem of behavior. Any flexible movement in nature, whether exhibited by what we call a living object or a dead, may readily be adjusted to this category without acquiring any added significance thereby. There is a wide distinction between an interpretation of a reflex movement as a reac- 
tion away from an injurious stimulus, or as an orientation by lines of force to bring about symmetrical impingement. Our experience with Æolosoma will not support the latter interpretation.

\section{BIELIOGRAPHY}

Brace, Edith M. 'oI-Notes on Æolosoma tenebrarum. Journ. Morph., xvii, p. 178 .

Bednard, F. E. '88-Observations on an Annelid of the Genus Æolosoma. Proc. Zoöl. Soc., p. 2 I3.

'92-Notes on an Encystment of Æolosma. Amer, Mag. Nat. Hy., ix, p. 12.

BонN, G. '05-Attractions et oscillations des animaux marins sous l'influence de la lumiere. Inst. Gen. Psy. Memoir I.

'o6-Attitudes et movements des Annelides An. Sci. Nat. 9 Series iii. 'o7-Interventions des réactions oscillatoires dans les tropismes. Contrés de Rheins.

'o8-Introductions à la psychologie des animaux a symmetrie rayonnée. Kribs Bull. Inst, Gen. Psy., i.

D’Udekem, J. '62-Notice sur les organes génitaux de Æolosoma. Bull. Acad. Roy. Belg., xxii, p. 533 .

EhrenberG, '27-Symbola Physicx. Berlin.

Holmes, S. J. '05-The Selection of Random Movements as a Factor in Phototaxis. Journ. Comp. Neur. and Psy., xv, p. 98.

Jennings, H. S. '97-Reactions to Chemical, etc., Stimuli in the Ciliate Infusoria. Journ. Phys., xxi, p. $25^{8}$.

'04-Contributions to the Study of the Behavior of the Lower Organisms.

Carnegie Inst. Pub.

'o6-Behavior of Lower Organisms. New York.

'o7-Behavior of Starfish. Univ. Cal. Pub., iv.

'08-The Interpretation of the Behavior of the Lower Organisms.

Science, n. s., xxvii, p. 698.

Loeв, J. '97-Zur Theorie der physiologischen Licht- und Schwerkraftwirkungen.

Pflüger's Archiv., p. 439.

'o3-Physiology of the Brain, p. 153. New York.

'05-(r889) Studies in General Physiology. Chicago.

'o6-Dynamics of Living Matter. New York.

'o8-Concerning the Theory of Tropisms. Journ. Exp. Zoöl., iv. p. I5I.

MAGGI, L. '65-Intorno al genera Æolosoms. Soc. Ital. Sci. Nat. i., p. 17. 
Massart, J. 'oI-Le lancement des Trichocysts. Bull. Ac. Roy. Belg., ii, p. 9. Mast, S. O. 'o9-The Reactions of Didinium nasutum, etc. Biol. Bull., xvi, p. 9I.

Nelson, J. A. 'b6-Note on Sex Organs of Æolosoma. Ohio Nat., vi, p. 435.

Pearl, R. 'o3-Movements and Reactions of Fresh-water Planarians. Quar. Jour. Mic. Sci., xlvi, p. $5 \circ 9$.

Vedjovsky, F. '84-System und Morphologie der Oligochæten. Prag.

'92-Ueber Encystirung von Æolosoma. Zool. Anz., xv. p. I71.

Walter, H. E. 'o7-Reactions of Planarians to Light. Journ. Exp. Zoöl., v, p. 35 . Stolc , A. '89-O poleovnich organech rodu Æolosoma. Sitz.-Ber Böhm. Ges. p. 183 . 